\title{
CFD Simulation of Fuel/flue Gas Section of the Fire-tube Steam Boiler System
}

\author{
P Sai Pavan Kalyan", Amol Deshpande ${ }^{2 *}$ \\ ${ }^{1,2}$ Department of Chemical Engineering, BITS Pilani K. K. Birla Goa Campus \\ Zuarinagar, Goa - 40326, India \\ ${ }^{1}$ h20180027@goa.bits-pilani.ac.in; \\ *Corresponding and presenting author: ${ }^{2}$ amoldeshpande@goa.bits-pilani.ac.in
}

\begin{abstract}
Fire tube steam boilers produce steam to be used in process heating applications. In these boilers, fuel and air are fed to the first zone called furnace zone, where combustion occurs and hot flue gases are produced. In the three pass boiler system these gases are passed in first and second convection zones having several tubes of smaller diameters. In the shell side of this boiler system, water flows at the desired flow rate. In the furnace and convection zones, heat is transferred to the water by radiation and convection. Water upon receiving heat gets converted to steam of desired pressure. In this process, temperature varies in the flue gas as well as in the water/steam side. It is important to know these variations for effectively designing the boiler system. Hence, a 3-D mathematical model was developed and CFD simulations were performed for the fuel/flue gas section of a fire tube boiler system using COMSOL Multiphysics $5.4^{\mathrm{TM}}$. The simulation results showed that the average temperature at the outlets of the furnace, convection zone - I and II are $1300 \mathrm{~K}, 500 \mathrm{~K}$ and $470 \mathrm{~K}$ respectively and that agrees well with the industrial operational data. The average velocities obtained in all these zones are also in agreement with the corresponding industrial data. This comparison validates the model and can be used for the effective and efficient design of the boiler system. Water and steam side simulations are currently in progress to predict water level fluctuations.
\end{abstract}

Keywords: Fire tube boiler, flue gas, CFD, heat transfer, modeling, COMSOL

\section{Introduction}

Steam is used as a working fluid in steam-turbines and as a hot utility to heat various streams in process industries like petroleum refining, steel manufacturing, pulp and paper, etc. [1]. Steam boilers are used to generate steam. Steam boiler equipment typically has fuel/flue gas and water/steam sections. Based on the flow of flue gases and water/steam, they are classified as water-tube boilers and fire-tube boilers. In water-tube boilers, the shell side contains the fuel and hot flue gases and water flows inside the tubes. These boilers have a higher heating surface area and are often used to generate steam at very high pressure, temperature and output capacities like in the application of electricity generation in power plants [2]. In the fire-tube boiler, water/steam is present in the shell side and fuel/hot flue gases flow through the tubes. These boilers typically are cheaper, more fuel-efficient and easier to operate. They can reach thermal efficiencies of about $70 \%$ and show consistent/reliable performance $[2,3]$. However, they are limited generally to capacities of $50 \mathrm{~kg}$ of steam/s and steam pressures of $4 \mathrm{MPa}$ because with an increase in steam pressure, thicker furnace/convection tubes are required that leads to an increase in the price of the boiler [3]. Hence they are not used for applications like electricity production but used in small scale applications that require hot water or steam of moderate pressures like district heating boilers, process industry boilers and other small steam generators [3]. The present study focuses only on the fire-tube boilers and its operational development.

Over the years, for the effective performance of such boiler systems, designs have been modified including control strategies and various operational changes have been suggested and implemented [4]. However, the challenges related to its operation still exist [4]. One of the important challenges is the shrinking and swelling phenomena occurring in the boiler steam drum. These are closely related to changes in pressure in the boiler due to variation in steam demand. When the pressure of the steam decreases, the level of the water in the drum increases causing the steam bubbles to expand, which is known as the swelling phenomenon. And if the pressure of the steam in the boiler drum increases, the level of the water decreases causing the steam bubbles to compress, which is termed as the shrinking phenomenon $[5,6]$. 
To address the operational challenges including shrinking and swelling phenomena, the fuel oil/gas combustion and convective heat transfer from flue gases to water/steam need to be controlled effectively which can be achieved by adjusting the operating parameters more efficiently. However, for developing effective methods to adjust these parameters and controlling heat transfer, it is very important to have accurate and detailed information about the fluid flow and heat transfer behavior in the fuel/flue gas section of the boiler. The dynamic modeling and CFD simulation can play a very important role in accurately predicting the temperature, velocity and pressure variations and hence the transport behavior in this section of the boiler system.

Mathematical models based on conservation laws have been developed and proposed to understand the dynamic behavior of the boiler system over the years. Most of these studies have focused on water-tube boilers [5-9] and relatively less work discuss the modeling of fire tube boilers [10-13]. A dynamic model of the fire-tube boiler comprising of numerous sub-models, each of which characterizes a different zone in the boiler, was proposed by Sorensen, K. in 2004 $[14,15]$. Each sub-model was developed with differential-algebraic equations given the corresponding physical principles. They have implemented and simulated the model in MATLAB. Their approach was useful in having the overall understanding of the transport behavior of the system, but as it was a relatively simplified model (based on sub-models) it could not predict the temperature variation in all the space dimensions at different times. Ortiz, F. J. G. (2011) and Tognoli, M. et al. (2018) have developed a basic 1-D model of the fire tube boiler and reported a comprehensive dynamic modeling procedure including a complex approach (by FEM) [16, 17]. They have considered most of the crucial physical phenomena happening in the boiler. Their approach provides results with acceptable accuracy and for relatively lower computational cost. Their model has found to be suitable for downsized boilers and has shown good dynamic performance without many losses. However, as it is a 1-D model, the information provided is limited. Some other dynamic models for the fire-tube boiler have been developed over the years to understand different design aspects of the boiler [18, 19], but detailed 3-D CFD model of such system (with different passes) has not been studied in detail so far.

In this work, a 3-D steady state CFD model of the 3 - pass fuel/flue gas section of one of the existing industrial firetube boiler system has been proposed. The corresponding modeling equations obtained based on mass, momentum and energy balances are presented. The models are implemented and simulated using a CFD software COMSOL Multiphysics $5.4^{\mathrm{TM}}$ which is based on the finite element method. The simulation results temperature and velocity variations in the different zones are reported and discussed in detail.

\section{Mathematical model}

A fire-tube boiler system has two main sections fuel/flue gas section (tube side) and water/steam section (shell side) Fuel/flue gas section is further divided into three different subsections, namely furnace zone, convection zone - I and convection zone - II. In all the three zones, heat is transferred by convection in the axial direction and is lost by radiation/surface convection to the water present in the shell side. In the furnace zone, the combustion of fuel oil (fuel considered in this case) with air occurs and heat is generated whereas in the convection zones there is no heat generation.

The assumptions considered while developing this model are as follows: (a) Axial conduction in the flue gas is neglected. (b) Radiation in the flue gas in convection zones is neglected. (c) Pressure variation in the radial direction is neglected (d) Combustion reaction is considered as instantaneous reaction as the fuel oil and air are reacted very fast and all the mixing is completely burnt to form flue gas. So, the kinetics of the combustion reaction is neglected. (e) Fuel consumption and air-fuel ratio are assumed constant. (f) Heat generation in the furnace zone is considered as equally distributed along the length [15]. Based on these assumptions and carrying out mass, momentum and energy balances, the model equations for the three zones have been obtained. The corresponding governing equations are given below.

\subsection{Governing equations}

Equation of continuity (mass balance):

$$
(\nabla \cdot(\rho u))=0
$$

Where $u$ is the velocity vector for flue gas 
Equation of motion: As the flow rate of gas in these zones is relatively higher, the $k$ - $\varepsilon$ turbulence model has been considered for determining momentum variation.

$$
\begin{gathered}
{[\nabla \cdot \rho u u]=(\nabla \cdot[-p I+K]+F)} \\
{[\nabla \cdot \rho k u]=\nabla \cdot\left[\left(\mu+\mu_{T} / \sigma_{k}\right) \nabla k\right]+P_{k}-\rho \varepsilon} \\
{[\nabla \cdot \rho \varepsilon u]=\nabla \cdot\left[\left(\mu+\mu_{T} / \sigma_{\varepsilon}\right) \nabla \varepsilon\right]+C_{\varepsilon 1} \varepsilon / k P_{k}-C_{\varepsilon 2} \rho \varepsilon^{2} / k} \\
K=\left(\mu+\mu_{\mathrm{T}}\right)\left(\nabla \mathrm{u}+(\nabla \mathrm{u})^{\mathrm{T}}\right)-(2 / 3)\left(\mu+\mu_{T}\right)(\nabla \cdot u) I-(2 / 3) \rho k I \\
\mu_{T}=\rho C_{\mu} \frac{k^{2}}{\varepsilon} ; P_{k}=\mu_{T}\left[\left(\nabla u:\left(\nabla u+(\nabla u)^{T}\right)-\frac{2}{3}(\nabla \cdot u)^{2}\right)-\frac{2}{3} \rho k \nabla \cdot u\right]
\end{gathered}
$$

Energy equation: Heat generation in the furnace zone is considered as a function of distance (Eq (11) [15]). Density is considered as a function of the temperature of the gas mixture and is represented by Eq. (12) (valid for $0^{\circ} \mathrm{C}$ to $1200^{\circ} \mathrm{C}$ ).

$$
\begin{gathered}
\left(\frac{\partial \ln (\rho)}{\partial \ln (T)}\right)_{p} \frac{D p}{D t}+\rho C_{p}(u . \nabla T)+\nabla . q=Q \\
\text { For furnace zone }\left(0<x<L_{F}\right) Q=\frac{Q g}{V} \text { or } Q=0 ; \text { where } V=\frac{\left(\pi * \mathrm{R}_{\mathrm{F}}^{2} * L_{F}\right)}{N S} \\
Q g=\dot{\mathrm{m}}_{f} * L H V *\left[\exp \left(-4 \cdot 6\left[\frac{x-\frac{L_{F}}{2 * N S}}{L_{F}}\right]\right)-\exp \left[-4.6 *\left(\frac{x}{L_{F}}\right)\right]\right] \\
\rho=2 \times 10^{-12} T^{4}-6 \times 10^{-9} T^{3}+7 \times 10^{-6} T^{2}-0.0038 T+1.2846\left[\mathrm{~kg} / \mathrm{m}^{3}\right]
\end{gathered}
$$

(Where $R_{\mathrm{F}}$ and $L_{\mathrm{F}} \rightarrow$ furnace chamber radius and length) (NS = No of segments in the axial direction (meshing elements))

Boundary conditions:

At the furnace inlet (at $x=0)$ :

$$
u=u_{\text {in }} ; T=T_{\text {in }}
$$

At the outlet (end of convection zone - II or chimney):

$$
p=p_{a t m} ; \frac{d T}{d x}=0
$$

At Furnace and tubes surfaces: At $r_{f}=R_{F}$ and $r_{t}=R_{t}\left(R_{\mathrm{t}} \rightarrow\right.$ radius of tubes in convection zones $)$

$$
-n \cdot q=h_{w}\left(T-T_{s}\right)+\varepsilon \sigma\left(T^{4}-T_{s}^{4}\right) ; \mathrm{u}=0
$$

(Where $T_{\mathrm{s}} \rightarrow$ saturated water temperature (water/steam side), $T \rightarrow$ fuel/flue gas temp) 


\section{CFD Methodology}

The fuel/flue gas section of an industrial 6 TPH fire tube boiler producing MP steam has been considered as a case study. The model of this section represented by above governing equations (Section 2.1) is implemented and subsequently simulated using CFD software COMSOL Multiphysics 5.4 ${ }^{\mathrm{TM}}$. The physical model of this section consisting of the furnace and two convection zones is shown in Fig. 1 (a) and (b) below. The furnace tube has a radius of $0.5 \mathrm{~m}$ and a length of $4 \mathrm{~m}$. The diameter and length of the tubes present in the convection zones are $32 \mathrm{~mm}$ and $4 \mathrm{~m}$ (Conv zone $-\mathrm{I}) / 4.5 \mathrm{~m}$ (Conv zone - II) respectively. There are two reversing chambers (RC 1 and RC 2). One connects furnace to the first convection zone and other connects zone I to zone - II.

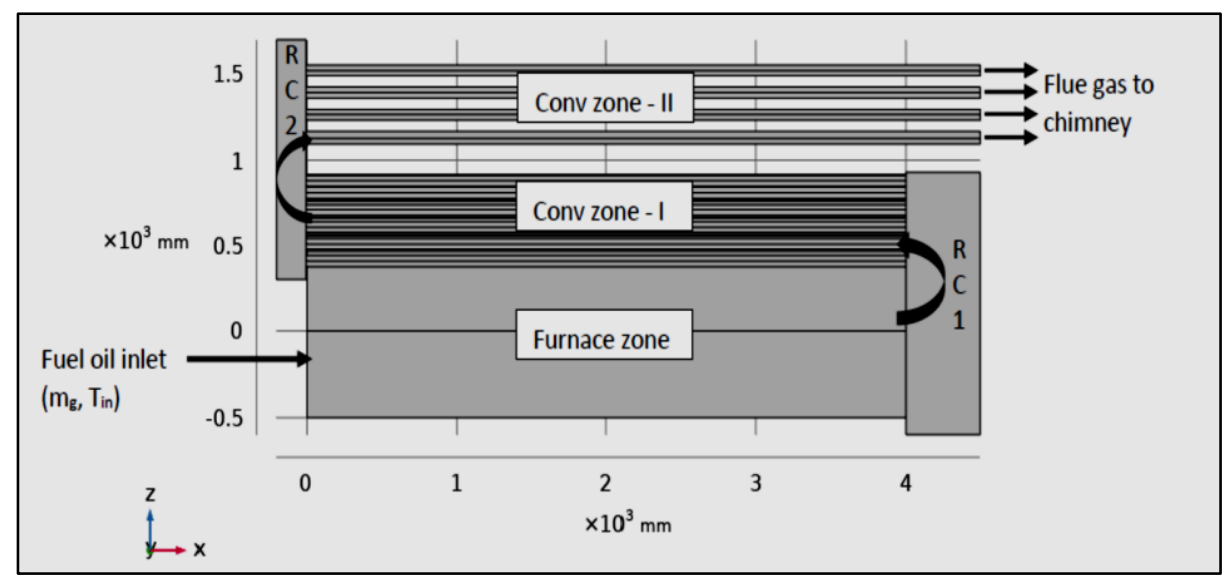

(a)

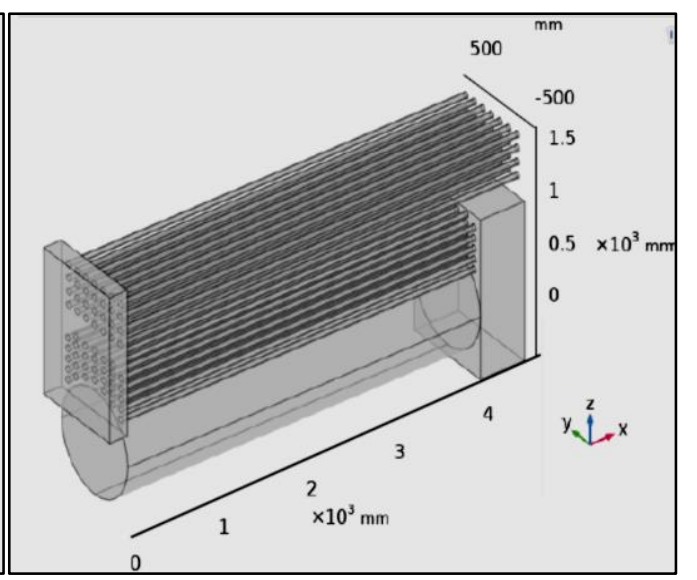

(b)

Fig. 1: Physical model (schematic) of the fuel/flue gas section of a considered fire tube boiler system (a) Front view (b) 3-D view

Fuel oil is considered as the fuel to be burnt. Suitable COMSOL modules were chosen for the considered section. The values/expressions of constants and variables along with appropriate boundary conditions for respective models were incorporated. The physical model was then divided into finite elements by meshing using an appropriate mesh size. Newton Raphson's non-linear method was used as an iterative method. The details related to COMSOL modules used, type of meshing, solver and convergence for in this study are given in Table 1 below.

Table 1: COMSOL - Modules/Meshing/Solver/Convergence related details

\begin{tabular}{|l|l|}
\hline COMSOL & (i) Turbulence flow k- $\varepsilon$ model \\
modules used & (ii) Heat transfer in fluids \\
\hline Meshing & Customized mapped and boundary layer distributed meshing \\
& Number of domain elements: 464973 \\
& Number of boundary elements: 257772 \\
& Number of edge elements: 50925 \\
\hline Solver & PARDISO \\
\hline Convergence & 0.0001 \\
\hline
\end{tabular}

\section{Results and Discussion}

The CFD simulation was then carried out for the considered system. The input parameters provided by the industry and used for the simulation runs are reported in Table 2. The simulation results are presented and analyzed in this section. 
Table 2: Parameters used in the simulation run

\begin{tabular}{|c|c|c|c|}
\hline Symbol/Parameter & Value & Units & Description \\
\hline$\dot{m}_{f}$ & 385 & {$[\mathrm{~kg} / \mathrm{h}]$} & $\begin{array}{c}\text { Mass flow rate of fuel (with composition C: } \\
\left.86.6 \mathrm{wt} \%, \mathrm{H}_{2}: 10.9 \mathrm{wt} \%, \text { Sulfur: 2.1 wt } \%\right)\end{array}$ \\
\hline $\mathrm{A} / \mathrm{F}$ & 16.5 & & Stoichiometric Air to fuel ratio \\
\hline$T_{\text {fuel }}$ & 378 & {$[\mathrm{~K}]$} & Inlet temperature of the fuel \\
\hline$T_{S}$ & 457 & {$[\mathrm{~K}]$} & Saturation temperature of water (MP) \\
\hline$L H V$ & 4037500 & {$[\mathrm{~J} / \mathrm{kg}]$} & Lower Heating Value of fuel \\
\hline$h_{w}$ & 6000 & {$\left[\mathrm{~W} / \mathrm{m}^{2} \mathrm{~K}\right]$} & Heat transfer coefficient on water side \\
\hline$C_{p g}$ & 1082.5 & {$[\mathrm{~J} / \mathrm{kg} . \mathrm{K}]$} & Specific heat of flue gas \\
\hline$K_{f g}$ & 0.13 & {$[\mathrm{~W} / \mathrm{m} . \mathrm{K}]$} & Thermal conductivity of flue gas \\
\hline$\varepsilon_{f}$ & 0.794 & & Emissivity of flue gas \\
\hline$N S$ & 50 & & Number of slices divided in the furnace \\
\hline $\mathrm{N} 1$ & 36 & & Number of tubes in convection zone $-\mathrm{I}$ \\
\hline $\mathrm{N} 2$ & 32 & & Number of tubes in convection zone - II \\
\hline
\end{tabular}

Fig. 2 shows the temperature surface plot of all the zones including reversal chambers. It shows that the temperature is highest in the furnace and reduces subsequently in the reversal chamber I, convection zone - I, reversal chamber - II, and is lowest in the convection zone - II. This indicates that the heat is being transferred from this section to the water section in all these zones. In the furnace zone, the temperature is observed to increase along the axis to a certain distance and then starts decreasing. This is because the heat generation due to the combustion of fuel dominates the heat transfer to the water in the initial section of the furnace. The temperature is also observed to be decreasing by few degrees in the radial direction towards the end of the furnace tube, indicating that there is conductive and convective radial heat transfer from the center of the tube to the surface, though this is not very significant as compared to axial convective heat transfer and heat transfer from the wall. The radial temperature variation in the convection zone tubes is negligible. Hence the axial temperature variation in each of these zones is important to be analyzed.

Fig. 3 presents the axial temperature variation in the furnace zone. The bulk average temperature calculated at each axial location (along the cross-section) is plotted along the axis. It shows that the temperature increases rapidly from an inlet temperature of $398 \mathrm{~K}$ to $1400 \mathrm{~K}$ (approximately) at $2.5 \mathrm{~m}$ and then starts decreasing slowly to reach a value of $1300 \mathrm{~K}$ at the end of the furnace. As explained earlier, it confirms that the heat generation due to the combustion of fuel oil is very high in the initial section (till $2.5 \mathrm{~m}$ ) of the furnace compared to heat transfer from the furnace walls to water. It balances out at around $2.5 \mathrm{~m}$ and convective heat transfer then starts dominating the heat generation causing the temperature to decrease. 


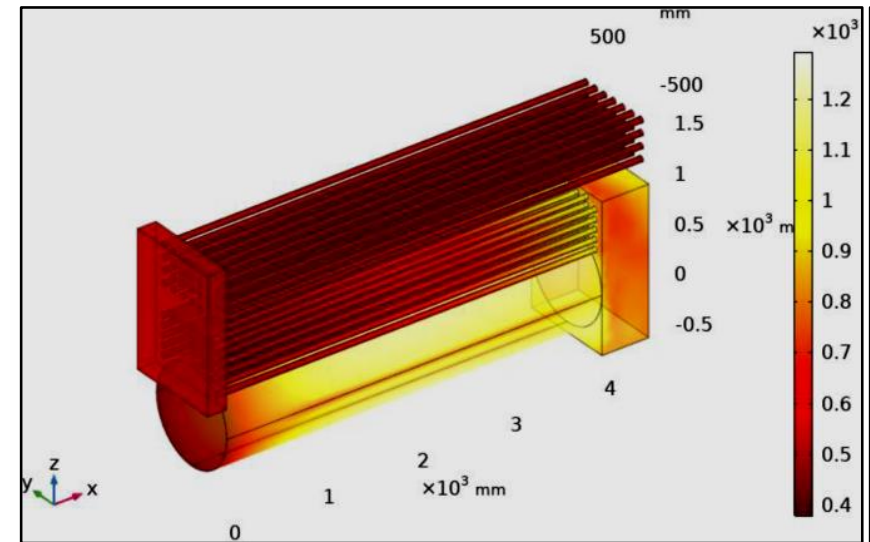

Fig. 2: Surface temperature plot in all zones (flue gas section)

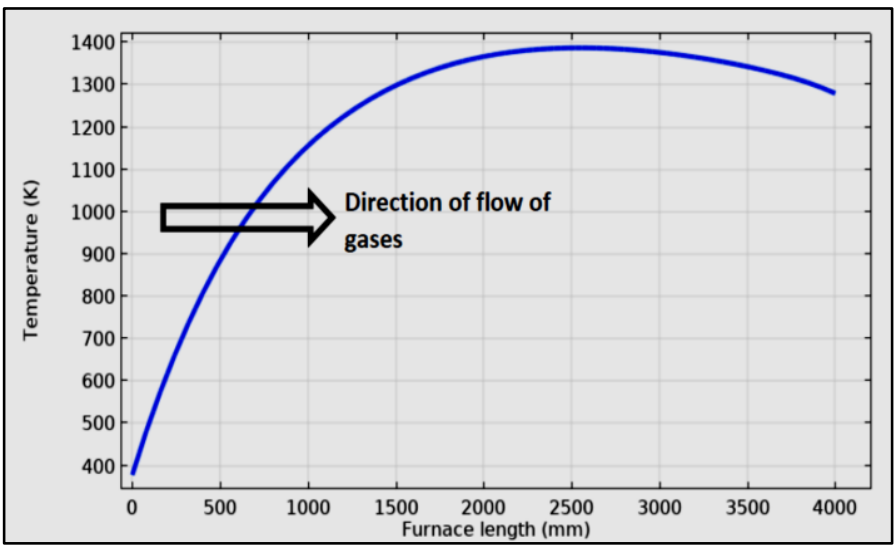

Fig. 3: Axial temperature profile in the furnace zone

Fig. 4 depicts the variation of temperature of flue gases along the axis of the tube in convection zone $-\mathrm{I}$. In this zone, the flow of flue gas is in the reverse direction of that in furnace/zone - II. At the inlet (i.e. at $x=4 \mathrm{~m}$ and after the gas flows through the reverse chamber - I), the temperature is $1150 \mathrm{~K}$ which indicates that the heat transfer has taken place in the reverse chamber - I as well and that has caused the temperature to drop from $1300 \mathrm{~K}$ to $1150 \mathrm{~K}$. In the zone - I, the continuous heat transfer takes place by surface convection (and to a certain extent by radiation) to the water. As shown in Fig. 4, the temperature of flue gas reduces with a relatively higher slope in the initial section from $1150 \mathrm{~K}$ (at $x=4 \mathrm{~m}$ ) to $700 \mathrm{~K}$ at $x=2.5 \mathrm{~m}$ ) and then reduces further till the end of the zone but with rather lower slope (i.e. from $700 \mathrm{~K}$ to $500 \mathrm{~K}$ in the remaining $2.5 \mathrm{~m}$ section of the tube). It is because the rate of heat transfer decreases along the axis of the tube due to the reduced temperature difference between the flue gas and saturated water.

In Fig. 5, the variation of temperature of flue gases in the axial direction in the tube of convection zone - II is indicated. In this case, the temperature decreases from $498 \mathrm{~K}$ to $470 \mathrm{~K}$. The temperature at the inlet of this zone (i.e. $498 \mathrm{~K}$ ) suggests that heat has been transferred in the reverse chamber - II but it is not significant. The reasons for variations of temperatures in this zone are similar to one explained for the zone $-\mathrm{I}$.

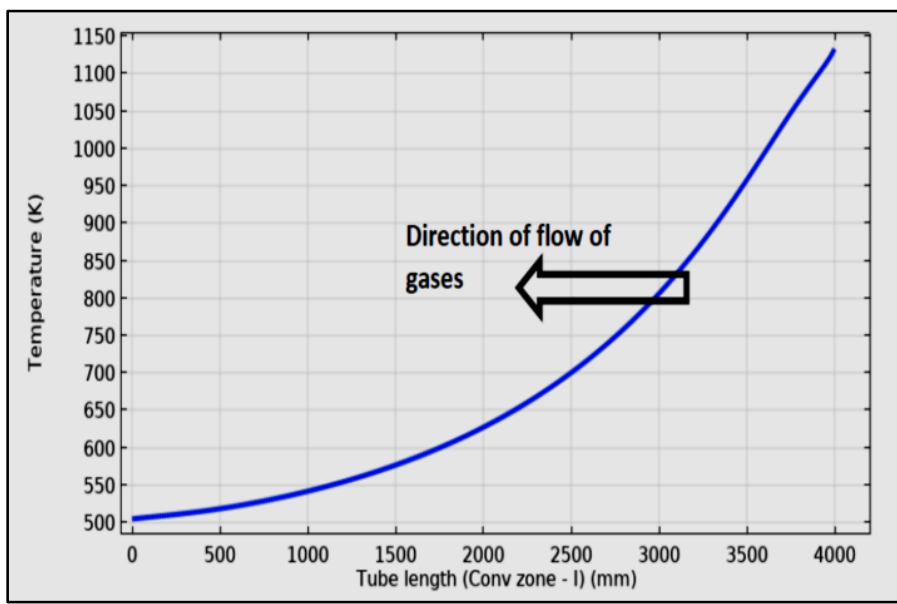

Fig. 4 Axial temperature profile in the convection zone - I

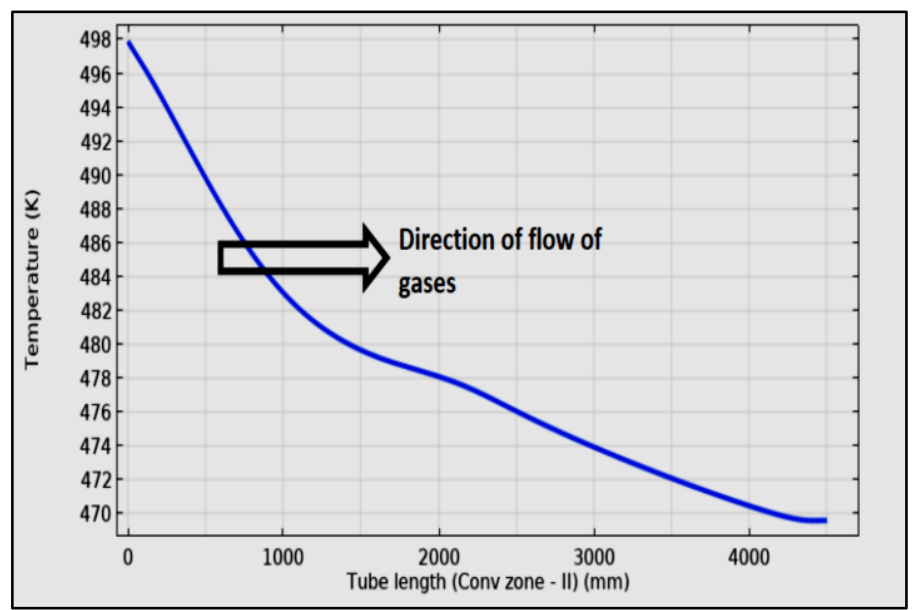

Fig. 5 Axial temperature profile in the convection zone - II

The temperatures obtained at the end of each zone $(1300 \mathrm{~K}, 500 \mathrm{~K}$ and $470 \mathrm{~K})$ have been compared with those obtained in the industrial fire-tube boiler $(1400 \mathrm{~K}, 590 \mathrm{~K}$ and $500 \mathrm{~K})$ operated using similar parameters and found to be in close agreement and trends are also similar. This comparison helps in validating the CFD model. 
The analysis of fluid flow behavior indicated that the velocity of the hot flue gas is close to $20 \mathrm{~m} / \mathrm{s}$ in the furnace zone and increases to $200 \mathrm{~m} / \mathrm{s}$ in the convection zones (due to reduction in the area of tubes). It is noticed that the velocity does not vary significantly in the radial direction and varies in the axial direction by a certain value, mainly because of the change in density which is varying with temperature. These average velocities are also found to agree with those observed in industrial fire tube boiler operation. This again confirms that the model is valid for the considered system. Hence this model can be used in the future for modifying the design/operation, understanding the corresponding effects on the operation and coming up with a robust/effective design of this section of the boiler.

\section{Conclusion}

A 3-D CFD model of fuel/flue gas section of the 3-pass industrial fire tube boiler system has been developed based on certain assumptions. Industrial boiler specifications and corresponding operating parameters were considered for the study. This model was implemented and simulated using COMSOL Multiphysics (a CFD software). The temperature and velocity variations in all the three zones (furnace, convection zones - I and II) were obtained. The model was validated by comparing the simulation results of bulk average temperatures at the outlet of each zone and average velocities with that observed in the practical operation of the boiler system and finding close agreement. Hence, the validated 3-D CFD model can play a very important role in understanding the operation of the boiler. We think that if this model (with few modifications in turbulent flow and heat generation terms) is developed further by integrating with that of the water/steam section of the boiler, it can be used as a basic 3-D CFD model of the fire-tube boiler system. This can help in studying the effects of various design/operating parameters and resolving the operational issues like swelling/shrinking phenomena and other related issues currently faced by the boiler users. The work on developing the CFD model for the water/steam section and integrating it with the fuel/flue gas section is currently in progress.

\section{Acknowledgments}

We acknowledge the support of the BITS Pilani K. K. Birla Goa campus, Goa (our institute) in purchasing the CFD software (COMSOL Multiphysics) that was used in this work. We are also grateful to Thermax Ltd., Pune for providing us the required design and operational data of the industrial fire-tube boiler system.

\section{Nomenclature}

Symbols

$\mathrm{A} / \mathrm{F} \quad$ Stoichiometric air to fuel ratio $\left[\mathrm{kg}_{\text {air }} / \mathrm{kg}_{\text {fuel }}\right]$

$C_{p} \quad$ Specific heat at constant pressure $[\mathrm{kJ} / \mathrm{kg} . \mathrm{K}]$

$C_{p g} \quad$ Specific heat of flue gas [J/kg. K]

$h_{w} \quad$ Heat transfer coefficient on water side $\left[\mathrm{W} / \mathrm{m}^{2} . \mathrm{K}\right]$

$k \quad$ Turbulent kinetic energy $\left[\mathrm{m}^{2} / \mathrm{s}^{2}\right]$

$K_{f g} \quad$ Thermal conductivity of flue gas [W/m. K]

$L H V$ Lower Heating Value of fuel $[\mathrm{J} / \mathrm{kg}]$

$L_{F} \quad$ Length of furnace [m]

$\dot{m}_{f} \quad$ Mass flow rate of fuel $[\mathrm{kg} / \mathrm{h}]$

NS Number of slices divided in the furnace

$p \quad$ Pressure $[\mathrm{Pa}]$

$q \quad$ Heat flux $\left[\mathrm{W} / \mathrm{m}^{2}\right]$

$Q g \quad$ Heat generated in the furnace [W]

$R \quad$ Radius of boiler $[\mathrm{m}]$

$R_{F} \quad$ Radius of furnace [m]

$R_{t} \quad$ Radius of tubes in convection zone [m]

$t$ Time [s] 


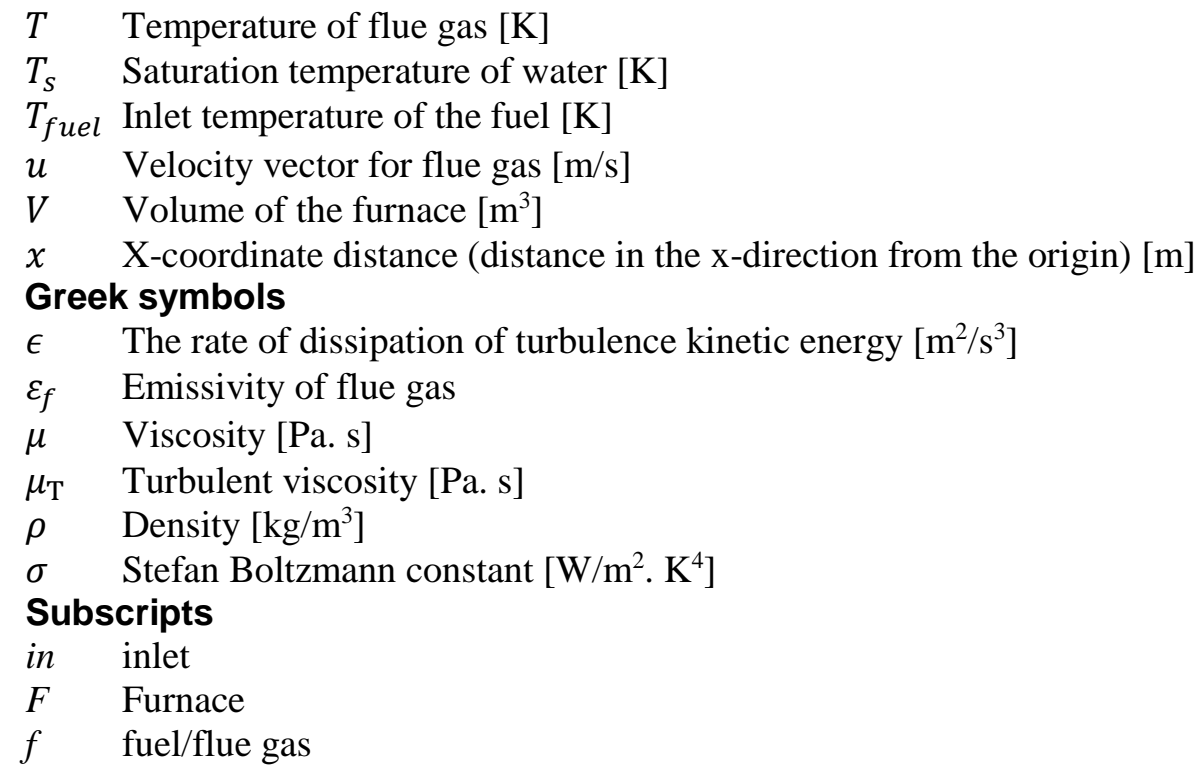

\section{References}

[1] K. Rayaprolu, Boilers: A practical reference. CRC Press, 2012.

[2] C. D. Shields, Boilers: Types, Characteristics, and Function. McGraw Hill, 1961.

[3] S. Kakaç, Boilers, evaporators, and condensers. John Wiley \& Sons, 1991.

[4] S. Teir, Steam boiler technology. Helsinki University of Technology (Esspo) publication, 2003.

[5] M. Iacob and G. Andreescu, "Drum-boiler control system employing shrink and swell effect remission in thermal power plants," 2011 3rd International Congress on Ultra Modern Telecommunications and Control Systems and Workshops (ICUMT), Budapest, 2011, pp. 1-8.

[6] S. Minhajullah, "Multivariable control of a drum-type boiler," M.Sc. thesis, Dept. Sys. Eng., King Fahd Univ. of Petroleum and Minerals, Saudi Arabia, 2011.

[7] H. E. Emara-Shabaik, M. A. Habib, I. Al-Zaharna, "Prediction of risers' tubes temperature in water tube boilers," Appl. Math. Model., vol. 33, no. 3, pp. 1323-1336, 2009.

[8] S. R. Tawfeic, "Boiler Drum-Level Modeling", J. Eng. Sci., Assiut University, Faculty of Engineering, vol. 41, no. 5, pp. 1812-1829, 2013.

[9] M. Y. Al-Awwad, "Experimental investigation of tube rupture under boiler dynamic operating conditions," M.Sc. thesis, King Fahd University of Petroleum and Minerals, Saudi Arabia, 2013.

[10] D. Gangadhara, K. Kumar, K. Naveen, "A numerical analysis of heat transfer enhancement in a boiler tube", IJIRSET, vol. 5 no. 3, pp. 3417-3425, 2016.

[11] S. P. Díaz, "Modeling and simulation of an industrial steam boiler with Ecosimpro," in 1st Meeting of EcosimPro Users, UNED, Madrid, 2001, pp. (5)1-(5)10.

[12] S. A. Khaustov, A. S. Zavorin, K. V. Buvakov, V. A. Sheikin, "Computer simulation of the fire-tube boiler hydrodynamics" in EPJ Web of Conferences (EDP Sciences), 2015, vol. 82, pp. 01039-p1-p5.

[13] B. J. Huang, P. Y. Ko, “A system dynamics model of fire-tube shell boiler” J. dyn. Sys., Meas., Control, vol. 116 no. 4, pp. 745-754, 1994.

[14] K. Sorensen, "Dynamic Boiler Performance: Modelling, simulating and optimizing boilers for dynamic operation," Ph.D. dissertation, Aalborg: Institut for Energiteknik, Aalborg Universitet, Denmark, 2004.

[15] K. Sorensen, C. M. Karstensen, T. Condra, N. Houbak, "Modeling and simulating fire tube boiler performance," in Proceedings of SIMS-Scandinavian Simulation Society, $44^{\text {th }}$ SIMS conference, Vasteras, Sweden, 2003.

[16] F. J. G. Ortiz, "Modeling of fire-tube boilers," Appl. Therm. Eng., vol. 31, pp. 3463-3478, 2011. 
[17] M. Tognoli, B. Najafi, F. Rinaldi, "Dynamic modeling and optimal sizing of industrial fire-tube boilers for various demand profiles," Appl. Therm. Eng., vol. 132, pp. 341-351, 2018.

[18] A. Bisetto, D. Del Col, M. Schievano, "Fire tube heat generators: Experimental analysis and modelling," Appl. Therm. Eng., vol. 78, pp. 236-247, 2015.

[19] W. Beyne, S. Lecompte, B. Ameel, D. Daenens, M. Van Belleghem, M. De Paepe, "The dynamic and steady-state performance model of fire tube boilers with different turn boxes," Appl. Therm. Eng., vol. 149, pp. 1454-1462, 2019. 